Section Editor

John J. Millichap, MD

Child Neurology:

\title{
Diagnosis and treatment of Tourette syndrome
}

A 16-year-old left-handed boy with Tourette syndrome (TS) presented to the outpatient neurology clinic complaining of difficulty focusing and completing tasks resulting in impairment at home, school, and social gatherings. He developed recurrent sniffing and throat clearing at age 6, which waxed and waned over time, and had since experienced repeated movements of the head, face, hands, and legs and gulping vocalizations; a diagnosis of TS was established at age 7. His tics were preceded by a premonitory sensation and were partially suppressible. These symptoms led to discomfort, but not impairment. He struggled with planning and organizational skills since age 6 , and at age 12 developed repeated washing and writing/ rewriting rituals. Family history was notable for a maternal grandmother with attention-deficit/hyperactivity disorder (ADHD) and a father with repetitive eye-blinking and possible childhood obsessive-compulsive disorder $(O C D)$. He had a normal birth followed by normal developmental milestones. Neurologic examination including smooth pursuit and voluntary saccadic eye movements was unremarkable.

TS is a developmental neuropsychiatric disorder characterized by multiple, recurrent, usually brief, nonrhythmic motor movements and at least one vocalization (motor and phonic tics, respectively) that have onset before age 18 , persist for 1 year, and are not due to medications or another medical condition. ${ }^{1}$ Simple motor tics may include eye blinking, head or shoulder jerks, or brief, sudden movements of the arms or legs; in contrast, complex motor tics vary widely and can include coordinated jerks of multiple muscle groups or repeated movements such as touching, hitting, or jumping. Simple phonic tics include throat-clearing, grunting, and sniffing; complex phonic tics consist of linguistically meaningful noises such as yelling obscenities (coprolalia), repetition of others' phrases or words (echolalia), and repetition of one's own words or phrases (palilalia).

Clinical characteristics. Tics are often first noticed between the ages of 5 and 9 years and typically reach peak severity in early to mid-adolescence followed by a tendency to wane in late adolescence. The few longitudinal studies of patients with TS suggest that tic severity and frequency tend to decline into early adulthood with only $10 \%-20 \%$ experiencing moderate to severe tics as adults. ${ }^{2}$ As tic severity decreases, comorbid psychiatric conditions often become the focus of treatment for adults with TS.

Epidemiology, differential diagnosis, and comorbidity. The population prevalence of TS in school-age children is approximately $0.3 \%-0.9 \%{ }^{3}$ with a male-to-female ratio of roughly 4:1, whereas chronic (persistent) motor or phonic tic disorder (motor or phonic tics persisting for $>1$ year) may be present in an additional $1 \%-2 \%$ of children. Furthermore, brief episodes of transient tics may be as high as $20 \%{ }^{4}$

The majority of children who experience tics have a primary tic disorder, and in the context of a typical history and normal neurologic examination, no additional laboratory testing or imaging is indicated. However, in children with co-occurring medical conditions, atypical presentation, or abnormal neurologic examination, it is appropriate to search for secondary causes such as inherited neurologic disorders (e.g., tuberous sclerosis, Wilson disease), infections (e.g., encephalitis), or medication side effects (e.g., tardive dyskinesia). In contrast to tics, which tend to start in the eyes, face, or head and shift over time to different body locations, complex motor stereotypies involve bilateral, often rhythmic, flexion/extension or pronation/supination hand or arm movements that have onset before age 3 and are not associated with emergence of new, distinct repeated movements elsewhere in the body. In addition, tics tend to wax and wane in severity and are briefly suppressible with subsequent rebound, unlike non-tic-related myoclonus.

Nearly $85 \%$ of participants with TS in a large, international study met criteria for a comorbid psychiatric condition, most frequently OCD and ADHD, and elevated rates of mood, anxiety, and disruptive behavior disorders. ${ }^{5}$ These comorbid disorders are often associated with more distress and impairment than tics themselves.

From the Department of Psychiatry (M.E.H.), University of California, San Francisco; Department of Neurology (M.E.D.), Boston Children's Hospital; Department of Neurology (M.E.D., J.M.S.), Psychiatric and Neurodevelopmental Genetics Unit, Center for Human Genetics Research (K.G.Y., J.M.S.), and Department of Psychiatry (J.M.S.), Massachusetts General Hospital; and Division of Cognitive and Behavioral Neurology (J.M.S.), Department of Neurology, Brigham and Women's Hospital, Boston, MA.

Go to Neurology.org for full disclosures. Funding information and disclosures deemed relevant by the authors, if any, are provided at the end of the article. 
Table Treatment approaches for tics, obsessive-compulsive disorder (OCD), and attention-deficit/hyperactivity (ADHD) disorder in patients with Tourette syndrome

Symptoms Behavioral approaches

Tics $^{1}$

OCD

ADHD generalization training)
Psychoeducation; comprehensive behavioral intervention for tics

Psychoeducation; cognitive-behavioral therapy (including graded exposure and response prevention followed by relapse prevention and

Psychoeducation; environmental modification (e.g., increased teacher-tostudent ratio); behavior modification

\section{Pharmacologic approaches}

$\alpha 2$ agonists (clonidine, guanfacine); atypical neuroleptics (e.g., risperidone, ziprasidone, aripiprazole); typical neuroleptics (e.g., haloperidol, pimozide, fluphenazine); other: tetrabenazine, topiramate, clonazepam, and baclofen

Selective serotonin reuptake inhibitors (SSRIs); for treatment-refractory cases: augmentation of SSRI therapy with an atypical antipsychotic (best evidence for risperidone); clomipramine

Stimulants: Methylphenidate, dexmethylphenidate, dextroamphetamine lisdexamfetamine; nonstimulants: atomoxetine, clonidine, guanfacine
Etiology. Findings from structural and functional MRI and resting-state functional connectivity studies among individuals with TS suggest that tics arise from abnormal development or maintenance of regulatory cortico-striatal-thalamo-cortical (CSTC) circuits. For instance, among adults with TS, there is evidence of aberrant structural connectivity within cortico-basal ganglia networks consistent with functional immaturity of CSTC circuits. Furthermore, these structural abnormalities were associated with tic severity. ${ }^{6}$

Although family studies have repeatedly demonstrated that TS is highly heritable, causative genes have been elusive. Recent studies have supported a complex, bilineal mode of TS inheritance consistent with polygenic transmission. Recent molecular genetic studies of TS examining cytogenetic abnormalities, copy number variants, genome-wide association of common variants, and rare mutations have been abundant, with few replicated findings.?

Treatment. Clinical trials support both behavioral and pharmacologic treatment modalities for youth with severe, distressing tics that interfere with daily functioning and quality of life. Among behavioral modalities, comprehensive behavioral intervention for tics (CBIT) has the strongest evidence-based support from randomized trials. CBIT combines stress-reduction skills with habitreversal training (HRT), a form of cognitive-behavioral therapy (CBT) in which patients are trained to become aware of tics before they occur and are taught competing behaviors to interrupt or inhibit the tic. Pharmacologic approaches for TS with the strongest evidence include $\alpha 2$ agonists and atypical and typical neuroleptics (table). ${ }^{1} \alpha 2$ agonists are generally considered first-line agents for pediatric TS, as the most common side effects (sedation, hypotension) are usually mild and there is good evidence demonstrating their efficacy. Youth with TS who either do not tolerate $\alpha 2$ agonists or continue to have tics may be switched to an atypical neuroleptic with moderate to high dopamine D2 receptor binding affinity (risperidone, ziprasidone, aripiprazole). These are generally well-tolerated in low doses but may increase the risk of metabolic syndrome and tardive dyskinesia. Finally, typical antipsychotics with the highest affinity for D2 receptors (haloperidol, pimozide, and fluphenazine) have been used the longest among any drug class to address tics; however, adverse effects include sedation, extrapyramidal symptoms, and QT-segment prolongation. As such, typical antipsychotics are now considered third-line agents for tic suppression and should typically be reserved for patients who do not respond to safer treatments. Limited evidence supports the use of tetrabenazine, clonazepam, topiramate, and baclofen. ${ }^{1}$

The patient's impairment due to inattention led to a diagnosis of ADHD. Medications trialed previously for TS included guanfacine, which was ineffective, and risperidone, which caused sedation. The patient and his family wanted to treat his attention problems but were concerned about stimulants; a previous trial of dexmethylphenidate had increased his tics.

Young patients with TS and comorbid ADHD frequently experience more impairment from $\mathrm{ADHD}$ symptoms than from tics themselves. Thus, while psychoeducation and behavioral therapy should be offered, if $\mathrm{ADHD}$ symptoms are severe enough, pharmacotherapy is often needed (table). Nonstimulant pharmacologic agents with good efficacy include the $\alpha 2$ agonists, atomoxetine, and desipramine; however, because stimulant medications are associated with larger effect sizes than nonstimulants, stimulants are typically considered to be first-line treatments. Contrary to general concerns, clinical trials of stimulants have demonstrated that stimulants do not necessarily worsen tics and that both tics and $\mathrm{ADHD}$ symptoms often improve with use of low-dose stimulants. ${ }^{8}$ A double-blind, randomized, placebocontrolled trial also demonstrated the efficacy of combined methylphenidate and clonidine in youth with tics and $\mathrm{ADHD}$ without any tic worsening relative to placebo. ${ }^{9}$ The most common side effects of stimulants in these trials included insomnia, decreased appetite, headache, gastrointestinal upset, and clinically nonsignificant increases in diastolic blood pressure and heart rate.

Given the patient's history of tic worsening on stimulants, he was started on clonidine followed by low-dose, immediate-release methylphenidate, titrated upward 
weekly to an optimal dose, and subsequently to extendedrelease methylphenidate. This dual therapy improved his tics and inattention but he continued to have difficulty initiating and completing tasks due to his perfectionism, which met criteria for $O C D$.

OCD and nonobsessive anxiety should be considered in the differential diagnosis of inattentive symptoms and difficulty completing homework. Comorbid OCD symptoms in youth with TS are addressed similarly to OCD without TS, namely using CBT with or without pharmacologic agents. Similar to tics, mild to moderate OCD should be addressed using behavioral approaches first, including graded exposure and response prevention (ERP), a form of CBT that involves training youth to tolerate premonitory urges or obsessions (exposure) and avoid compensatory compulsions (response prevention). Pharmacologic approaches include selective serotonin reuptake inhibitors (SSRIs), the tricyclic antidepressant clomipramine, and SSRI augmentation with risperidone. The combination of CBT and pharmacologic agents is generally more effective than either alone. ${ }^{10}$

The patient was started on citalopram and initiated $C B T$ for $O C D$ as well as CBIT/HRT for residual tics. Combined behavioral and pharmacologic treatment improved his tics and his ability to complete homework and tasks but he continues to struggle with intrusive thoughts.

When treating patients with TS, it is important to consider the interplay between tics and symptoms arising from TS-related comorbidities such as OCD, $\mathrm{ADHD}$, and anxiety.

A combination of an $\alpha 2$ agonist and a low dose of stimulant improved the patient's tics and partially improved attention, but his attention is still impaired by symptoms related to obsessive and nonobsessive anxiety. These symptoms will need continued treatment and monitoring.

\section{AUTHOR CONTRIBUTIONS}

M.E. Hirschtritt: drafting/revising the manuscript for content, including medical writing for content; study concept or design. M.E. Dy: drafting/revising the manuscript for content, including medical writing for content; acquisition of data. K.G. Yang: drafting/revising the manuscript for content, including medical writing for content; acquisition of data. J.M. Scharf: drafting/revising the manuscript for content, including medical writing for content; acquisition of data; study concept or design; study supervision or coordination.

\section{STUDY FUNDING}

No targeted funding reported.

\section{DISCLOSURE}

M. Hirschtritt, M. Dy, and K. Yang report no disclosures relevant to the manuscript. J. Scharf has received research and travel support from the Tourette Association of America, serves on the Scientific Advisory Board of the Tourette Association of America and the Trichotillomania Learning Center, and has received consulting fees from Nuvelution Pharma, Inc. Go to Neurology.org for full disclosures.

\section{REFERENCES}

1. McNaught KS, Mink JW. Advances in understanding and treatment of Tourette syndrome. Nat Rev Neurol 2011;7: 667-676.

2. Bloch MH, Peterson BS, Scahill L, et al. Adulthood outcome of tic and obsessive-compulsive symptom severity in children with Tourette syndrome. Arch Pediatr Adolesc Med 2006;160:65-69.

3. Scharf JM, Miller LL, Gauvin CA, Alabiso J, Mathews CA, Ben-Shlomo Y. Population prevalence of Tourette syndrome: a systematic review and meta-analysis. Mov Disord 2015;30: 221-228.

4. Snider LA, Seligman LD, Ketchen BR, et al. Tics and problem behaviors in schoolchildren: prevalence, characterization, and associations. Pediatrics 2002;110:331-336.

5. Hirschtritt ME, Lee PC, Pauls DL, et al. Lifetime prevalence, age of risk, and genetic relationships of comorbid psychiatric disorders in Tourette syndrome. JAMA Psychiatry 2015;72:325-333.

6. Worbe Y, Marrakchi-Kacem L, Lecomte S, et al. Altered structural connectivity of cortico-striato-pallido-thalamic networks in Gilles de la Tourette syndrome. Brain 2015; 138:472-482.

7. Pauls DL, Fernandez TV, Mathews CA, State MW, Scharf JM. The inheritance of Tourette disorder: a review. J Obsessive Compuls Relat Disord 2014;3:380-385.

8. Cohen SC, Mulqueen JM, Ferracioli-Oda E, et al. Metaanalysis: risk of tics associated with psychostimulant use in randomized, placebo-controlled trials. J Am Acad Child Adolesc Psychiatry 2015;54:728-736.

9. Tourette's Syndrome Study Group. Treatment of ADHD in children with tics: a randomized controlled trial. Neurology 2002;58:527-536.

10. Pediatric OCD Treatment Study (POTS) Team. Cognitivebehavior therapy, sertraline, and their combination for children and adolescents with obsessive-compulsive disorder: the Pediatric OCD Treatment Study (POTS) randomized controlled trial. JAMA 2004;292:1969-1976. 


\section{Neurology}

\section{Child Neurology: Diagnosis and treatment of Tourette syndrome}

Matthew E. Hirschtritt, Marisela E. Dy, Kelly G. Yang, et al.

Neurology 2016;87;e65-e67

DOI 10.1212/WNL.0000000000002977

This information is current as of August 15, 2016

\section{Updated Information \&} Services

\section{References}

Subspecialty Collections

Permissions \& Licensing

Reprints including high resolution figures, can be found at: http://n.neurology.org/content/87/7/e65.full

This article cites 10 articles, 1 of which you can access for free at: http://n.neurology.org/content/87/7/e65.full\#ref-list-1

This article, along with others on similar topics, appears in the following collection(s):

\section{ADHD}

http://n.neurology.org/cgi/collection/adhd

All Clinical Neurology

http://n.neurology.org/cgi/collection/all_clinical_neurology Child psychiatry

http://n.neurology.org/cgi/collection/child_psychiatry

Tourette syndrome

http://n.neurology.org/cgi/collection/tourette_syndrome

Information about reproducing this article in parts (figures,tables) or in its entirety can be found online at:

http://www.neurology.org/about/about_the_journal\#permissions

Information about ordering reprints can be found online:

http://n.neurology.org/subscribers/advertise

Neurology ${ }^{\circledR}$ is the official journal of the American Academy of Neurology. Published continuously since 1951, it is now a weekly with 48 issues per year. Copyright @ 2016 American Academy of Neurology. All rights reserved. Print ISSN: 0028-3878. Online ISSN: 1526-632X.

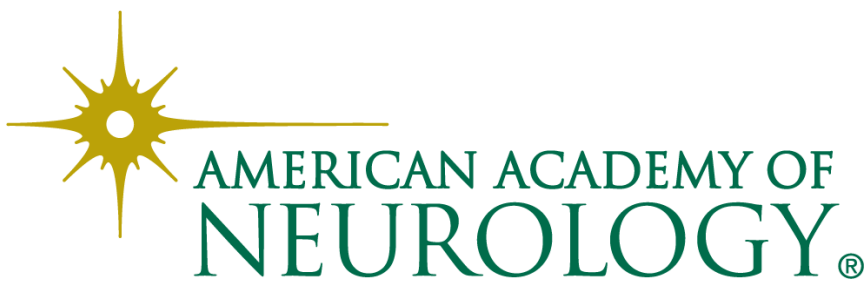

